\title{
Editorial
}

\section{Look alike sound alike drugs: From hospitals to homes}

\author{
Shantanu Rastogi* \\ Department of Pediatrics, Maimonides Infants and Children's Hospital, Brooklyn, NY, USA
}

Received 18 June 2011

Accepted 18 June 2011

Competition and decreasing resources are forcing health care organizations to reduce cost, eliminate waste, increase productivity and most importantly, ensure patient safety [1]. It is essential to improve quality of health care to meet these goals. The Institute of Medicine published a report "Crossing the quality chasm" describing the six goals of health care quality. These are effective, efficient, timely, safe and equitable patient-centered care. Despite huge strides made by the healthcare industry there are major gaps in the performance of healthcare systems and the quality desired. These represent a significant risk to the patient safety [2]. Medical errors are one of the leading causes of patient mortality and morbidity. An earlier report from Institute of Medicine reported medical errors could be responsible for up to 100,000 deaths annually [3].

Healthcare systems lag behind the manufacturing industry by many decades in quality improvement. The methods which have improved manufacturing are new to medicine. In the industry, the basis of all quality improvement lies in the concept of 'systems' [4]. Systems are an interdependent group of items, people, and processes working together towards a common purpose. They are complex and dynamic and have profound effect on quality improvement. Donebedian's model of system is the gold standard currently being implemented to improve quality in healthcare systems [5]. It consists of

*Address for correspondence: Shantanu Rastogi, SUNY-HSC at Brooklyn, Attending Neonatologist, Maimonides Infants and Children's Hospital, Brooklyn NY, USA. E-mail: srastogi@maimonidesmed.org. structure, process and outcomes. The activity of each component and the interaction with each other defines the output from the system. Hence, the expected output can be determined by the measure of these components. Examples of measures of structure include the human and material resources such as education, certification and experience of the clinicians in the hospital. These are easily accessed but lack process details such as appropriate actions taken for an intended outcome and how they were performed according to guidelines and policies are examples of process. Outcome measures report the changes in the health status of the patient following a set of processes, using the given structure in a system. It measures rates such as mortality rates for various diseases [6]. Given the substantial overlap in the population utilizing normal saline as well as rash protector spray, failure of the manufacturers of normal saline, and rash protector spray, to package their products in a distinctive manner, as reported by Parikh et al. [7], is a flaw in the structure component of the systems. Such mistakes are the fourth commonest cause of medicinal errors [8]. Look alike sound alike (LASA) medicines have similar packing or sounding names as chosen by the pharmaceutical industry and food and drug administration without realizing the similarity of new drugs' names or packaging with the older drugs in the market [9]. Due to its significance, it was defined as a patient safety goal by the joint commission in 2005. It required organizations like hospitals to identify and, at a minimum, annually review a list of LASA drugs and to proactively implement safety strategies to help prevent medication errors involving 
these drugs. Proactive assessment of potential for medication errors included evaluation of potential look-alike packaging problems in addition to the sound alike drug names [10].

The recent identification of similar packing of the nasal spray and rash protector spray demonstrate that although this patient safety goal has been propagated by The Joint Commission, products still continue to be available, particularly among those which are over the counter. Extending these goals to the health care industry beyond hospital setting will further help identify LASA drugs, thereby substantially contributing to patient safety.

\section{References}

[1] National Research Council (US) Committee on Future Directions for Behavioral and Social Sciences Research at the National Institutes of Health; Singer BH, Ryff CD, editors. New Horizons in Health: An Integrative Approach. Washington (DC): National Academies Press (US); 2001.
[2] Mangione-Smith R, DeCristofaro AH, Setodji CM, Keesey J, Klein DJ, Adams JL, et al. The quality of ambulatory care delivered to children in the United States. N Engl J Med 2007;357:1515-23.

[3] Institute of Management. To err is human. Washington DC: National Academy Press; 1999.

[4] Nolan TW. Understanding medical systems. Ann Intern Med 1998;128(4):293-8.

[5] Donabedian A. Evaluating the quality of medical care Milbank Mem Fund Q 1966;44:166-206.

[6] Rastogi S, Olmez I, Bhutada A, Rastogi D. NCI classification of thrombocytopenia in extremely preterm neonates and its association with mortality and morbidity. J Perinat Med 2011; 39(1):65-9.

[7] Parikh P, Jonna S, The TG. Chemical pneumonitis from rash protector spray- a case report. J Pediatr Intens Care 2011.

[8] Jones JH, Treiber L. When the 5 rights go wrong: medication errors from the nursing perspective. J Nurs Care Qual 2010; 25(3):240-7.

[9] Davis NM, Cohen MR, Teplitsky B. Look-alike and soundalike drug names: the problem and the solution. Hosp Pharm 1992;27(2):95-8, 102-5, 108-10.

[10] McCoy LK. Look-alike, sound-alike drugs review: include look-alike packaging as an additional safety check. Jt Comm J Qual Patient Saf 2005;31(1):47-53. 